\title{
Prazer e sofrimento de líderes em uma organização familiar
}

\author{
Pleasure and suffering of leaders in a family business \\ http://dx.doi.org/10.5007/2178-4582.2014v48n2p352
}

\author{
Elaine Marinho Bastos, Antonio Caubi Ribeiro Tupinambá \\ e Suzete Suzana Pitombeira \\ Universidade Federal do Ceará, Fortaleza/CE, Brasil
}

\begin{abstract}
Os trabalhadores encontram-se inseridos em um contexto de mudança, o que tem exigido rápida adaptação causando efeitos de natureza física e psíquica. Neste estudo investiga-se o prazer e o sofrimento psíquico dos líderes em uma organização familiar. Para isso, procurou-se identificar a existência do prazer e as estratégias de defesa utilizadas em situações de sofrimento. Buscou-se, também, conhecer a percepção de sete líderes em relação às condições de trabalho no exercício da gestão. Um estudo de caso descritivo, de caráter qualitativo, foi desenvolvido mediante entrevista como técnica de coleta de dados. Identificou-se, por meio das falas dos sujeitos pesquisados, situações de sofrimento relacionados às categorias: contexto da organização de trabalho; formação e qualificação dos líderes; e estratégias defensivas. Uma relação entre prazer, sofrimento e organização do trabalho na empresa familiar pesquisada foi percebida, evidenciando-se situações que significam, para os líderes, vivência de prazer no cotidiano de trabalho associada a sofrimento.
\end{abstract}

Palavras-chave: Prazer - Sofrimento - Trabalho - Empresa Familiar
Workers are inserted into a changing context that has demanded a fast adaptation causing effects of both mental and physical natures. In this study, the pleasure and the mental suffering of leaders in a family business are investigated. Thus, we tried to identify the existence of pleasure and the defensive strategies used in suffering situations. We also sought to be aware of the perception of seven leaders in relation to working conditions in the exercise of management. A descriptive case study, of qualitative method, was developed by using interviews as the data collection technique. It was identified from the speeches of the researched individuals, suffering situations related to the following categories: Work and organizational context, Training and qualification of leaders and Defensive strategies. A relation between suffering and work organization in the researched family business was noticed, highlighting situations that mean, to the leaders, the experience of pleasure in daily work associated to suffering.

Keywords: Pleasure-Suffering - Work - Family Business

\section{Introdução}

As mudanças que se processam no mundo do trabalho, decorrentes da reestruturação produtiva, com a incorporação de novas tecnologias, heterogeneização, fragmentação e complexificação de estratégias gerenciais, além do aumento acelerado da força de trabalho inserida no setor informal, pressupõem um novo perfil de trabalhador, uma nova ordem de inserção e de atuação 
profissional na organização. Essas mudanças no mundo do trabalho atingem a classe trabalhadora, sua subjetividade, afetando sua forma de vivenciar o trabalho, (ANTUNES, 2013). Os trabalhadores encontram-se cada vez mais inseridos nesse contexto de mudança, e essas mudanças têm exigido rápida adaptação causando efeitos de natureza física e psíquica. Esses efeitos podem ser negativos para a saúde, assim como podem contribuir positivamente para o bem-estar dos trabalhadores. El-Batawi (1988) enfatiza o trabalho como fator de fomento à saúde, não se devendo, portanto, subestimar os seus aspectos positivos e efeitos estruturadores.

As mudanças no mundo do trabalho provocam um impacto na vida dos indivíduos que são coagidos a conviver com uma lógica de mercado oscilante, em constante ameaça, vista como um mal inevitável nos tempos modernos (DEJOURS 2003). Nesse sentido, o complexo ambiente de mudança que atinge o mundo do trabalho tem impacto direto sobre o trabalhador, que vivencia, objetiva e subjetivamente, essa realidade no exercício de suas atividades.

Considerando-se que esse cenário tem contribuído para a modificação do panorama da saúde e qualidade de vida do trabalhador, objetivou-se investigar o prazer e o sofrimento psíquico dos líderes no contexto do trabalho em uma organização familiar. Para isso, procurou-se identificar a existência de prazer e de sofrimento e as estratégias de defesa utilizadas para lidar com situações de sofrimento. Buscou-se, também, conhecer a percepção dos pesquisados em relação às condições de trabalho no exercício da liderança.

Para a devida contextualização teórica, apresenta-se a importância social e psíquica do trabalho com aspectos do trabalho na organização familiar, bem como a liderança na empresa familiar. A seguir, o percurso metodológico, a análise dos dados e apresentação dos resultados. As considerações finais fecham o texto.

\section{Trabalho: importância social e psíquica}

O trabalho pode ser entendido por meio de um universo de significados: sacrifício, sobrevivência, realização, formador da identidade, status social, cujas transformações ocorridas no tempo e na história trouxeram implicações aos modos de viver dos trabalhadores (GRISCI, 1999). Nesse sentido, o trabalho pode dar origem a processos de alienação e mesmo de descompensação psíquica, como pode ser fonte de saúde e instrumento de emancipação. O labor pressupõe não somente uma preocupação com a eficácia técnica, mas busca incorporar argumentos de proteção e de realização do ego, relativos ao viver em comum, ao mundo social. Assim, o trabalho não é somente a execução de atividades produtivas, mas também é espaço de convivência (DEJOURS, 2003). 
Dejours (2004) apresenta a ideia de que o trabalho não pode ser pensado separado do social, pois este compõe a identidade do sujeito. Assim como para Lacombe (2005), o trabalho é parte essencial da vida do homem, uma vez que constitui aquele aspecto de sua vida que lhe dá status e o liga à sociedade. Em concordância, Castro e Merlo (2011) expõem que, para se compreender o trabalho, é preciso levar em consideração o social, bem como o contexto do indivíduo.

Segundo Mendes (2007) o trabalho é percebido como um elemento central estruturante, organizador da sociabilidade e fundamental na construção da identidade, com perspectiva de promoção de saúde e equilíbrio mental. Ele ocupa um lugar de destaque no cotidiano por estar ligado à necessidade de sobrevivência e de auto-realização, influenciar a constituição de redes de relações sociais, trocas afetivas e econômicas, e auxilia no processo de aprendizado, na interação e na forma de consolidação da identidade pessoal e social.

Os estudos sobre trabalho têm se tornado cada vez mais pertinentes, em função de constantes mudanças nas organizações, com consequências que interferem diretamente em todo o processo e gestão das organizações, na vida e no cotidiano do trabalhador. Cada vez mais os trabalhadores são inseridos em contextos diversificados, com crescente individualização, concretizando o estranhamento e a alienação do cotidiano, sem possibilidade de visualização do processo produtivo como um todo, fato considerado fundamental para a satisfação no trabalho (JACQUES; CODO, 2002).

Dejours (2003) define o trabalho como carga física e psíquica, uma modalidade de resolução de conflitos e de regulação da vida psíquica e somática, modo privilegiado de equilíbrio, com a participação em um contexto coletivo, inserindo novos hábitos, além de uma carga psíquica difícil de quantificar, diferentemente da carga física. Esse trabalho pressupõe espaço de exigências, tais como o tempo e o ritmo no qual o corpo é inicialmente o ponto de impacto, neutralizando a atividade mental de quem o pratica.

$\mathrm{O}$ trabalho influencia e transcende o seu tempo de jornada propriamente dita, estendendo-se para a vida particular, com efeitos sobre a família, interferindo nas relações sociais do não trabalho, direta ou indiretamente. A influência do trabalho também deve ser considerada nas relações sociais, nas trocas afetivas e econômicas e, em perspectiva psíquica, no alicerce e na constituição do sujeito, com uma rede de significados.

Quando o trabalho perde sua significação, deixando de ser motivo de orgulho e satisfação, despersonaliza-se e dificulta a compreensão da significação da ação, no conjunto da atividade da organização. O trabalhador que não compreende a finalidade do trabalho que realiza pode se sentir inútil, com 
desapropriação da liberdade, da expressão e da invenção, levando ao sofrimento psíquico.

Situações negativas obrigam o trabalhador a desenvolver mecanismos de defesa para manter-se sadio e apto para o trabalho. Segundo Dejours (2007), a "normalidade" apresentada não advém da ausência de sofrimento; pelo contrário, ela é alcançada através de uma batalha contra a desestabilização psíquica provocada pelas situações impostas no trabalho de conteúdos empobrecidos das tarefas, isolamento e monotonia, rigidez e interdições. Trata-se de uma conquista mediante uma luta feroz entre as exigências do trabalho e a ameaça de desestabilização psíquica e somática.

O trabalho possui, portanto, influência direta na saúde mental do trabalhador de forma positiva ou negativa. No entanto, durante muito tempo, o trabalho não foi pensado como parte do conjunto de aspectos significativos no adoecimento das pessoas, de modo a ser considerado também um fator de constituição de prazer ou sofrimento psíquico. Há contextos de adoecimento interligados ao trabalho, tornando-se necessário aprofundar o debate sobre sua relação com a saúde mental, bem como a importância sobre o reconhecimento dessa relação como forma de garantir amparo ao trabalhador (DEJOURS, 1997).

A insatisfação, em relação ao conteúdo significativo da tarefa, gera um sofrimento cujo ponto de impacto é, antes de tudo, mental, em oposição ao sofrimento resultante do conteúdo ergonômico da tarefa. Portanto, sofrimento mental resultante de uma frustração em nível do conteúdo significativo da tarefa pode levar a doenças somáticas (DEJOURS, 1992, p.61). As somatizações podem ser definidas, entre outros modos, como o processo através do qual os conflitos profundos do âmbito psíquico, uma vez não resolvidos satisfatoriamente, usam a via corporal para conhecer um necessário alívio, levando a transtornos manifestados no corpo (TURATO, 2003, p. 92).

A somatização, portanto, pode ser uma resposta individual ao sofrimento no trabalho, na qual o indivíduo encontra uma saída que se manifesta por meio da doença, pois não pode abandonar ou mudar o contexto do emprego, rígido em sua estrutura, uma vez que este é o meio de sua subsistência. Percebe-se que a somatização mascara o sofrimento mental.

Para Jacques (2007), existem possibilidades de não adoecimento. O prazer no trabalho está ligado a uma consonância entre os anseios, desejos e aspirações do trabalhador e aquilo que o contexto de produção pode oferecer. Alguns aspectos são de fundamental importância para o estabelecimento do prazer no trabalho, nomeadamente: flexibilização da organização do trabalho; visualização do processo de produção em todo o seu contexto, isto é, com 
começo, meio e fim da atividade; utilização de métodos e instrumentos de trabalho mais adequados; identificação com o trabalho a partir da constatação da totalidade dos resultados e objetivos; maior autonomia; uso de competências técnicas e criativas e relações sociais baseadas na confiança, cooperação e participação.

Caso essas situações não sejam vivências cotidianas, acarretam situações de sofrimento como uma vivência individual ou compartilhada pelo grupo com experiências de angústia, medo e insegurança, resultantes da impossibilidade de uma negociação bem-sucedida entre os desejos e anseios individuais e o contexto de produção do trabalho e de sua organização.

\section{O trabalho na organização familiar}

Para um bom entendimento do universo pesquisado é necessário definir a organização familiar. Tomou-se como referência Lodi (1998), que identifica essa organização com uma família, por uma relação de parentesco, cuja ligação resulta de uma influência recíproca na política geral, normas, interesses aspectos culturais e objetivos da organização e família. Origem e história da organização são vinculadas, portanto, a uma família e seus membros estão inseridos e regendo diretamente a organização e sua gestão.

O mesmo autor ainda aponta outras características das organizações familiares: laços familiares determinam cargos, ações dos membros da empresa refletem na reputação da organização, protecionismo e paternalismo, empregos e promoções por favoritismos, etc. O fundador é quem desenvolve o negócio, criando uma forma particular de cuidar dele, geralmente demonstrando orgulho, rigidez, dedicação e lealdade, com questões emocionais interferindo nas relações, o que influencia, por seu turno, a cultura organizacional.

Segundo Kets de Vris (2009), as empresas familiares são uma realidade no mundo organizacional e vêm crescendo nos últimos anos, pois as pessoas estão buscando, na abertura de um negócio próprio, obter maior independência profissional e possuir maior controle sobre suas próprias vidas. $\mathrm{O}$ referido autor afirma que empresa familiar é qualquer organização de negócios em que as decisões e a liderança são influenciadas por famílias.

O perfil diferenciado de uma organização familiar tem como características a influência de relações emocionais, com contatos pessoais e a rigidez em suas cobranças incluindo, segundo Lodi (1998), valorização da confiança, dedicação, relações autoritárias e paternalismo, com processos decisórios que tendem ao improviso, dentre outras que influenciam decisões e processos. Essas organizações tendem a experimentar instabilidade nos processos e na 
organização do trabalho, acarretando medo e insegurança diante de variáveis e preferências afetivas que interfiram nas relações, podendo, consequentemente, desencadear o sofrimento de seus trabalhadores com normas e formas influenciadas por fatores pessoais.

As organizações familiares representam a possibilidade de uma maior absorção de mão de obra e geração de empregos. São responsáveis pela sustentação da economia e aquecimento do mercado, e são as mais afetadas pela globalização, segundo Lanzana (1999). Além de serem a forma mais antiga de organização comercial, e principal fonte de criação de riquezas e empregos, são consideradas propulsoras do bem-estar social e econômico de toda a economia capitalista.

Para Lodi (1989), fazer parte de uma empresa familiar é algo que afeta os trabalhadores em suas vidas profissionais e carreiras, pois existe a interferência direta da cultura familiar nos processos internos e culturais da organização. História, identidade, valores, tradições, prioridades e linguagem da família fundadora passam a fazer parte da cultura da organização. Estrutura organizacional, liderança, estratégia, administração financeira e comportamento organizacional em empresas familiares diferem daquelas sem vínculos familiares (MACEDO, 2000). A influência da família no negócio compromete, de forma positiva ou negativa, o modo de atuação e de inserção da organização. Essa influência também é percebida no cotidiano de trabalho, pois a atividade e a rotina estão associados à indicação da família e do líder fundador.

De acordo com Lodi (1989), os papéis da família e da empresa são confusos na empresa familiar. A lealdade e a confiança dos funcionários são valorizadas como critérios de promoção, há instabilidade no seguimento das normas implantadas e o não questionamento das mesmas, mudanças constantes das normas, a valorização do critério de antiguidade, etc. Pode-se observar, também, algumas características negativas, como falta de disciplina, personalização dos problemas, uso indevido dos recursos, falta de sistema de planejamento e controle, utilização de critérios de familiaridade para contratação e promoções, fatores que interferem na motivação dos demais funcionários. Tais características influenciam os resultados da empresa e a atuação dos trabalhadores, pois as normas e ordens são subjetivas e levam em conta questões relacionadas a sentimentos e afetividade.

\section{Liderança na empresa familiar}

Embora o termo liderança seja frequentemente usado na literatura sobre comportamento nas organizações, em muitos casos existe uma quantidade razoável de mal-entendidos sobre seu verdadeiro significado e dificuldades em definí-lo. 
Segundo Bowditch (2011), a liderança pode ser considerada como um processo de influência, através da qual um indivíduo ou grupo é orientado para o estabelecimento e atingimento de metas; capacidade de gerenciar um grupo de pessoas, influenciando de forma simbólica e não coercitiva as atividades dos membros de um grupo, e fazendo com que a equipe alcance os objetivos propostos pela organização.

Bergamini (2006) a define como a habilidade de conduzir pessoas de forma natural, em conformidade com as características e normas próprias dos diferentes grupos. Um dos pontos mais importantes na liderança, apontado por este autor, é que o líder só é seguido se for admirado por seu seguidor, pois líder não é só uma determinada combinação de traços, mas um padrão de características pessoais que deve manter a atividade e o objetivo dos seguidores.

Robbins (2000, p.371) entende a "liderança como o processo de influência pelo qual os indivíduos, com suas ações, facilitam o movimento de um grupo de pessoas rumo a metas comuns compartilhadas". Com essa perspectiva, pode-se entender que existe um processo de influência que caracteriza um relacionamento recíproco entre líder e liderado, não caracterizado necessariamente por um processo de domínio e poder, mas sim, através da cooperação e motivação dos membros. Segundo Kwasnicka (2004, p.89) "a influência é qualquer ação ou exemplos de comportamento que causam mudança de atitude ou de comportamento em outras pessoas ou grupos".

Schein (2009) trabalha com o tema liderança envolvendo a questão cultural da organização, unindo liderança e cultura, definindo o perfil da liderança de uma organização como uma variável crítica a partir do fracasso ou sucesso de determinadas ações. A criação da organização é influenciada por seus fundadores líderes, que definem o perfil dos líderes que assumirão futuramente a função, relacionando assim cultura e liderança.

\section{Percurso metodológico}

A pesquisa realizada teve abordagem qualitativa e descritiva com a intenção de mostrar a realidade de uma organização familiar, no que tange à relação de trabalho dos líderes e sua condição de prazer e sofrimento psíquico. Utilizou-se o método de estudo de caso e aplicação de entrevistas que ajudassem a visualizar o contexto a ser conhecido em profundidade. Segundo Gil (2008), o estudo de caso permite a proximidade entre o pesquisador e os fenômenos estudados, com aprofundamento das questões levantadas, investigando a partir de um contexto real e possibilitando levantar informações e proposições com apropriações particulares. 
Gil (2008) define entrevista como uma técnica qualitativa de apreensão da percepção e da vivência pessoal das situações e dos eventos do mundo. Segundo o autor, a entrevista explora um assunto a partir da busca de informações, percepções e experiências de informantes para serem posteriormente analisadas e apresentadas de forma estruturada.

A organização pesquisada é voltada para atividades na área de varejo, funcionando na cidade de Fortaleza (CE), e tem unidades em bairros diferentes dessa cidade. Sete líderes dessa organização foram selecionados por meio do critério de conveniência e acessibilidade. O número de participantes atendeu à sugestão de Barker, Pistrang e Elliot (2002), que consideram ser possível obter a saturação dos dados em estudos qualitativos a partir de amostras entre 5 e 10 participantes, levando-se em conta que serão utilizadas entrevistas com grande nível de expansão do assunto, com eixos temáticos definidos.

O perfil sócio-demográficos dos sujeitos da pesquisa estão descritos na Tabela 1:

\section{Tabela 1- Perfil sócio-demográfico}

\begin{tabular}{llll} 
Idade & Gênero & Tempo de empresa & Nível de escolaridade \\
\hline 18 a 25 anos=2 & Masc. 5 & Até 1 ano=1 & Educação básica=5 \\
26 a 32 anos=3 & Fem. 2 & De 1 a 5 anos=3 & Ensino Superior=2 \\
33 a 39 anos $=2$ & & Mais de 5 anos=3 & Especialização=0 \\
Mais de 40 anos $=0$ & - & - & - \\
\hline
\end{tabular}

Fonte: Elaborada pelos autores

A coleta de dados, por meio de entrevista, utilizou uma pergunta de partida, que possibilitou a expressão do sujeito a partir de sua percepção e vivência. Quando necessário, havia a intervenção dos pesquisadores para o melhor entendimento da fala e do contexto apresentado. A pergunta apresentada inicialmente foi: "O que é ser líder para você?", utilizando-se de eventuais perguntas complementares também voltadas ao objetivo da pesquisa.

$\mathrm{Na}$ análise dos dados obtidos foi utilizada a análise de conteúdo (AC) (BARDIN, 2009) como forma de apreender as informações necessárias para o entendimento do discurso, buscando interpretar o que está escondido e latente na mensagem, interligando significantes com significados. Segundo Vergara (2005), a análise de conteúdo é uma técnica de tratamento de dados que visa identificar o que está sendo dito sobre determinado tema, relacionando posteriormente a uma teoria levantada que dá suporte ao estudo e avaliação das falas, focalizando as peculiaridades e as relações entre os elementos, enfatizando o que é significativo e relevante. Uma técnica para se estudar e analisar a comunicação de forma sistemática e objetiva, que busca a essência de um 
texto nos detalhes das informações, trabalhando como detalhe do contexto, inferindo-se sobre o todo da comunicação.

A codificação e categorização foi dividida em três etapas: recorte dos conteúdos, definição das categorias analíticas e categorização final das unidades de análise. Seguindo essa sistemática, realizou-se a análise e organização do material coletado, decompondo e recompondo os relatos, selecionando os elementos e fragmentos do discurso dos entrevistados manifesto em palavras, frases, expressões ou ideias que constituíram as unidades de análise, classificação ou registro. Em seguida, esses elementos do discurso dos entrevistados foram agrupados de acordo com a filiação dos sentidos, organizando as devidas categorias analíticas que não são fixas no início, mas tomam forma no curso da análise. Por fim, tem-se uma categorização final, quando se realiza a análise, reconsiderando os conteúdos e a interação entre eles.

\section{Resultados}

As entrevistas aplicadas aos sete líderes de uma empresa familiar, que deram base ao atual estudo, foram transcritas para, a seguir, se identificar o que viria a compor os conjuntos temáticos a serem analisados. Após o recorte dos conteúdos, estes foram agrupados e identificados nas seguintes categorias centrais de análise: Contexto da organização de trabalho; formação e qualificação dos líderes; liderança: atividade de responsabilidade; sofrimento ou prazer; e estratégias defensivas.

\section{Contexto da organização de trabalho}

Esta categoria apresenta o contexto e organização do trabalho como um dos pontos que exercem influência nas atividades de trabalho dos líderes, bem como em suas percepções, relacionando-o à condição psíquica de trabalho. $\mathrm{O}$ trabalho é caracterizado como um conjunto de gestos, formas do fazer cotidiano que engloba o saber fazer, o engajamento do corpo diante de um ambiente ambivalente e com potencial e sentimentos.

Como aponta Dejours (1997), o determinante da organização do trabalho e o conteúdo da tarefa realizada substituem o livre arbítrio através da divisão do trabalho e das condições impostas. As condições de trabalho, somadas a uma organização de trabalho desorganizada e exploradora, interferem e adoecem o corpo, envolvem e limitam o psíquico, desencadeando sofrimento. Estando diante de situações implantadas por um outro, que ignora a individualidade e a subjetividade, podendo causar infelicidade, alienação, doença física e mental, mas, por outro lado, contraditoriamente, pode 
servir de mediação da auto-realização e saúde, conforme se apreende da fala dos líderes 3 e 5 .

Tudo jogado, as pessoas não têm respeito, tudo é cheio de processos, normas, gente para responder... (lider 3)

A estrutura das lojas são boas, dá para trabalhar legal. O que perturba é esse negócio de mudança: um dia de um jeito, um dia de outro... acaba que todos reclamam...sem saber o que é para fazer hoje. (lider 5)

A dificuldade de adaptação às constantes mudanças a partir da ordem familiar e independente de negociação com os colaboradores, as características da atual organização com suas decisões, e a sua liderança influenciadas por membros da família são características intrínsecas de uma organização familiar e as pressões por resultados estabelecidos por critérios próprios da direção são desencadeadoras de situações de conflito e sofrimento.

Gosto da empresa, gosto do dono, mas com tantas mudanças que acontecem e coisas que não são explicadas, do dia para a noite. Metas que não tem explicação e se não superar os pontos sabe que vai ter problemas. (líder 3)

Geralmente o que se quer é bater a meta, que é alta viu! Tenta fazer com que dê certo, mas se não der muda logo... isso que é ruim. (lider 5)

O sofrimento surge diante das relações com a organização e com os outros, levando a um reflexo no corpo. São relatos de somatizações, tais como dores no peito, arritmias, gastrites e afastamentos por dores sem diagnóstico. A hostilidade para com os que adoecem surgiu como um dificultador na demonstração e fala desses sintomas. Os sujeitos estão expostos, a todo o momento, a variados tipos de controle, no meio em que vivem.

Nos discursos, percebe-se um conteúdo manifesto que indica, de forma latente, o sofrimento por que passam. As pessoas tendem a calar perante situações de mal-estar, buscando formas de adaptação; o sofrimento é relativamente silenciado e controlado através das estratégias de defesa que podem ajudar a não desenvolver eventuais patologias.

Sinto muitas dores de cabeça depois de um dia pesado de trabalho. Final de mês éo pior período porque a gente tem a meta para bater e sabe que se não fechar vai ter problema. Nesses dias a mulher nem deixa os meninos chegar perto de mim, sabe que eu vou brigar com eles. (líder 3) 
Assim, observa-se que a forma de organização do trabalho tem influência direta sobre o sofrimento dos líderes da empresa investigada, tendo, inclusive, a interferência da questão familiar nesse processo. Ademais, isso também ocorre a partir da importância que é dada ao líder fundador diante das mudanças na organização.

O dono não aparece mais como antes. Antes era melhor, agora, sem ele, tudo desandou. (líder 3)

Faço pelo seu João (nome fictício do fundador da organização), ele já me ajudou muito... ele é uma boa pessoa, gosta de ajudar, mas como ele não tá tão perto... ai tudo mudou. (líder 2)

O dono é legal, conversa com a gente, mas é estressado se não tiver do jeito que ele quer...dá problema (lider 5).

Essa influência da família, bem como dos "donos" no negócio, que compromete de forma positiva ou negativa a atuação dos seus colaboradores e sua perspectiva de inserção, estão presentes no discurso dos colaboradores, sempre ratificando o seu peso e sua importância. Influência percebida no cotidiano de trabalho, no qual a atividade e a rotina se associam ao núcleo da família e ao líder fundador. A lealdade e a confiança dos funcionários dependem do elo formado com os administradores familiares, que pode determinar também o grau de estabilidade em seguir as normas implantadas e o seu não questionamento.

\section{Formação e qualificação dos líderes}

Esta categoria apresenta a necessidade, revelada pelos entrevistados, por formação e capacitação para a função específica de líderes, pois a situação encontrada é de indicação, sem a qualificação e preparação necessárias para o exercício da função. A realidade é de implantação de uma cultura que reproduz o jeito de ser da organização e o comportamento indicado pelos diretores, no contexto de ambiência da organização.

Dejours (2007) afirma que uma organização de trabalho, concebida como serviço especializado, com mudanças implantadas por um outro, torna-se estranha, chocando-se com a vida mental, motivação e desejo do trabalhador. A insatisfação em relação ao conteúdo da tarefa tem um impacto, antes de tudo, na mente e na subjetividade. Essa forma de organização, socialmente construída, tem papel central na determinação do sofrimento mental, caso não exista uma reorganização ou adaptação. Torna-se, portanto, necessário certo nível de informação e treinamento para que as atividades sejam feitas a contento, tendo 
em vista se tratar de um serviço especializado para não se tornar estranho e desestimulante, aos olhos de seus executores.

Os entrevistados apontam que não existe uma formação ou desenvolvimento para que consigam exercer a função de líderes, mas que na verdade são escolhidos e indicados a desenvolver as atividades de responsabilidade como líderes, sem profissionalização ou qualificação adequada, o que se pode apreender das falas em todos os líderes entrevistados.

Apesar do nível da educação formal não estar necessariamente e diretamente associado à formação e à competência da liderança, vale a pena salientar que o quadro de líderes da atual organização tem, na maioria dos seus membros, uma escolaridade apenas básica. Ademais, há queixas de que a formação para o cargo é feita a partir de experiência pessoal pura, sem acompanhamento profissional ou formal com critérios para a construção da liderança organizacional, o que pode gerar estilos de liderança diversos e incompatíveis com as metas organizacionais, por serem improvisados e sem maiores reflexões ou fundamentações. Ademais, isso dificulta a aprendizagem a partir de erros de modo mais sistematizado, o que seria essencial para a formação de líderes mais autoconfiantes:

Antigos que trabalham demais e viram encarregados sem estar preparados para a função, são burro de carga que viram chefes, não são líderes, não sabem liderar. Conhecem o produto, mas sem liderança desenvolvida, metem os pés pelas mãos.(lider 1)

Não tem treinamentos, nada que ajude no cotidiano de trabalho. A gente aprende fazendo... é legal, mas as vezes faz errado...aí já viu! (líder 2)

A gente não é formado para isso, sem treinamentos, é empurrado literalmente, hoje tá diferente, tem umas seleção ai, mas antes... você era empurrado. (lider 3 )

Nunca fui ensinado, aprendi fazendo as atividades... fui vendo e fui fazendo. Acho que é assim mesmo, se aprende fazendo... ou você faz ou tá fora, então vamos fazer. (líder 4)

O encarregado precisa conhecer bem sua função, lidar bem com sua equipe, saber o aspecto técnico para poder ensinar e ajudar. A gente aprende fazendo sabe, acho que ser lider é o dia a dia, lidar com sua equipe, dividir com eles as metas e quando a gente chega lá.(lider 5)

Assim, percebe-se a necessidade de uma qualificação, pois a liderança é influência. Por não haver esse critério, sentem-se pouco preparados, refor- 
çando o fato de que liderança é formada no cotidiano de trabalho no contexto familiar da organização. Como o papel principal do líder é "guiar" sua equipe para conseguir resultados, é necessário que haja uma preparação para tais funções. Uma vez que falta essa preparação percebem-se situações de pressão e cobrança que podem levar a condições de sofrimento.

\section{Liderança: atividade de responsabilidade e sobrecarga}

Nesta categoria é apresentada a responsabilidade da função de líder e a sobrecarga que tal atividade pode causar. Dejours (2007) apresenta que os níveis de sofrimento psíquico são elevados, mas as pessoas tendem a calar perante às situações geradoras de mal-estar, buscam adaptação ao trabalho pela responsabilidade de que são cobrados, pela inserção no importante mundo do trabalho, etc. Encarregados são definidos como líderes, responsáveis por sua equipe, em funções de baixa remuneração, com relativa autonomia e grande responsabilidade de gerir inúmeras disfunções da organização familiar que, segundo os entrevistados, não lhes resultam em recursos e retornos necessários para fazer frente às exigências de seu trabalho. Ao mesmo tempo, lhes é exigido - mesmo sem essa contrapartida de recursos - que intensifiquem de forma crescente seus ritmos de trabalho. Talvez essa maneira de nomear os líderes da organização, cobrando-lhes um papel de liderança em dimensão tão limitada, termine por lhes imprimir mais um exercício de função gerencial do que aquele atribuído à liderança. Segundo Tupinambá (2012), o conhecimento sobre liderança é (des)construído permanentemente, como a própria experiência dos líderes e de suas organizações. A polivalência é citada como um fator que aumenta a tensão. No caso, a polivalência é inerente ao trabalho dos encarregados, tornando-os alheios ao que entendem por ser líderes, frustrando-os profissionalmente:

Não são preparados para a função... são jogados e aprendem fazendo. Tomar de conta do balcão, tomar de conta de muitas pessoas que não querem mais trabalhar é muito complicado, mas é o que deve ser feito. Horas-extra e muito trabalho, responsável por pedidos, tudo de acordo, sem pedir nada demais, sem faltar nem sobrar. (lider 1)

Ser responsável pelos outros não é legal, mas tem gente que é legal. Uns ajudam, outros não. Tem que fazer pedido, chegar cedo, sair tarde, atender os clientes, ouvir os funcionários, abastecer, cuidar das validades, dos promotores, é muita coisa pra gente fazer. (lider 2)

Atender bem, acho que isso é o mais complicado, com tudo que a gente tem que fazer; e eu gosto, gosto de atender, mas 
tem dias que é difícil, tem muita coisa, muita gente olhando, cobrando e pouca gente ajudando... é dificil. Responder ao dono sobre as coisas, quando ele vem nas lojas. É uma cobrança minha mesmo... de tá fazendo a coisa do jeito certo, do jeito que eu sei que ele vai gostar...ele agradece, dá parabéns, mas se tiver errado...(risos) ai ele briga, e briga muito.(líder 3)

Muita sobrecarga de responsabilidade, se funcionários não fazem, vou lá e faço. Pedidos, com gerente estressado, gente que se acha, que pode maltratar a gente. Abrir e fechar loja é o mais dificil, faço plantão, e isso me sobrecarrega, mas gosto, aprendo...é legal, sim...o que você aprende fica para você. (lider 4)

A separação entre momento de trabalho e folga não é tão nítida no contexto atual; essa situação altera a vida dentro e fora do trabalho. Mesmo aquele que se encontra em uma situação aparentemente privilegiada, como a de um líder, com vínculos de trabalho aparentemente estáveis, experimentam a insegurança e a competição, vivendo a precariedade do trabalho, uma precariedade subjetiva do trabalho, coerente com o que se tem testemunhado, e que vem caracterizando o atual mundo trabalho.

Familia fica em segundo plano. Falta de tempo para cuidar da saúde, estudos, a gente fica muito tempo aqui. Pressão grande, cobrança, nivel de stress alto para todos, mas encarregados ainda mais. (lider 1)

Problemas familiares, briga com a esposa, estamos mais para lá do que para cá. Cansaço por ficar direto, sobrecarga de atividades, cansaço, mas não consigo descansar bem.(lider 2)

\section{Sofrimento ou prazer?}

Nesta categoria é apresentada a existência do sofrimento ou prazer no cotidiano de trabalho. O sofrimento no trabalho é consequência de experiências dolorosas, tais como angústia, medo e insegurança, instalado quando a realidade não oferece as possibilidades de gratificação de seus desejos. Seligman e Silva (1994) afirmam que o trabalho poderá fortalecer a saúde mental ou levar a distúrbios que se expressarão em termos sociais, psíquicos, psicossomáticos ou psiquiátricos.

A forma de trabalho dominado, característico do mundo hodierno, produz o sofrimento na medida em que a dominação esmaga a identidade e a aprisiona à estrutura organizacional. Existe uma busca por transformar percepção da organização do trabalho, mas com pouca eficácia, como reforçado pelos en- 
carregados, pela rigidez da normatização da organização. O prazer é a consonância do desejo, anseios e aspirações diante do contexto que lhes é oferecido. Essas vivências são tecidas no cotidiano de trabalho, interpretando a realidade e reagindo de forma física, mental e afetiva.

Nos discursos dos entrevistados, percebe-se um comportamento manifesto que indica, de forma latente, o sofrimento por que passam, tendendo a se calarem perante situações de mal-estar e buscando formas de adaptação:

Eu sentia stress, me abalava com o cliente, me afastava do balcão, dava as costas, ia para a pia, oferecia outras coisas, não queria me indispor com o cliente. (líder 3)

Sou novo, gosto do que faço, mas as cobranças são grandes, às vezes dá vontade de desistir. Queria ser gerente, mas não sei mais... Com tanta sobrecarga e responsabilidade de trabalho. Você fica sem tempo para estudar, muita coisa errada que você fica sendo responsável sem ser. Gosto do que faço, mas tem horas que penso em desistir, é muito pesado, muita pressão, cobrança, responsabilidade. (líder 4)

Sinto dores pelo corpo pela sobrecarga de trabalho. Não acho certo o encarregado passar por isso, mas fazer o que, né. Dores no corpo são diárias, dores de cabeça as vezes. Gosto do meu trabalho, mas dá trabalho ser encarregado. Não tenho tempo para a familia, os dias de folga são para descansar, mas a mulher reclama desse cotidiano, mas até acho que ela tá acostumada.(lider 5)

Vale a pena ressaltar que o trabalho também pode ser fonte de equilíbrio e produtor de prazer (DEJOURS, 1997). Nos discursos dos líderes entrevistados se apresentam determinadas situações de prazer, por exemplo, aquelas em que revelam experiências positivas a partir das atividades profissionais desenvolvidas na organização. Para os entrevistados, ser líder é poder trabalhar com certa autonomia, o que também demonstra prazer no exercício do trabalho. Observa-se, ainda, que em muitos casos na organização familiar a liderança tem um perfil de negação do sofrimento alheio, inclusive calando o seu.

Mal vejo minha família, chego em casa, o menino tá dormindo; saio, ele tá dormindo. Todo dia é bem corrido, mas é assim mesmo, eu gosto do que eu faço, ser líder das pessoas é bom, responsabilidade. (líder 5)

A gente, muitas vezes tem papel de proteção da equipe. A gente faz isso, com o pessoal e usa o afetivo para conquistar. A gente amacia. Muitas vezes vêm coisas absurdas, que tem que usar e fazer, porque eu me dou conta que não dá para mudar uma 
coisa desagradável. Então, a gente tem que ter aquele jogo de cintura, ter uma habilidade de conseguir fazer funcionar, porque conflito é ruim pra todo mundo.(líder 5)

Prazer versus sofrimento é um conceito dialético, que coexiste e é inerente ao trabalho; um trabalho como lugar de significações psíquicas e construção de relações sociais, interações e representação humana:

Estou tomando remédios mais fortes, fluoxetina. Tomando só 1 de manhã, mas vinha trabalhar com atestado, porque é da gente, fico agoniado, querendo fazer muitas coisas ao mesmo tempo.(líder 3)

As pessoas às vezes se distanciam, são grosseiras e a gente fica sem saber o que fazer. E tem que aguentar e também segurar as pontas das cobranças e os problemas que a gente tem, as coisas pessoais.(lider 4)

Alguns sentimentos indicadores de sofrimento, tais como indignidade, inutilidade, desqualificação e vivência depressiva são percebidos na fala dos entrevistados. Assim como a confirmação de condições de adoecimento decorrentes do esgotamento de tentativas de adaptação dos sujeitos ao trabalho:

Muita dor de cabeça, palpitação. Dor no peito, tinha dia que eu pensava que tava com problema no coração, fui no cardiologista e ele disse que não...era só stress. Tem dias que a cabeça só falta explodir, é ruim, ruim. Tomo remédio, mas não passa. Passo o dia mal.(lider 3)

\section{Estratégias defensivas}

Nesta categoria são apresentadas as defesas criadas, segundo Dejours (1997), diante das condições de trabalho oferecidas pela organização, isto é, uma alternativa para o não adoecimento. As defesas estratégicas são processos mentais, pois não modificam a realidade imposta pela organização; são diferentes e necessárias para a proteção da saúde mental, desenvolvidas de acordo com a identidade e subjetividade do trabalhador, cumprindo papel paradoxal, porém capital nas motivações da dominação pois permitem que os trabalhadores se mantenham ativos em seus trabalhos, adaptando-se a pressões que lhes sejam causadas (DEJOURS, 2007). Trata-se de situações sutis, cheias de engenhosidade, variedade e invenção na busca de modificação, transformações ou minimização da sua percepção da realidade que lhe é imposta na organização de trabalho: 
Tem que beber umas cervas e tentar ficar melhor. Saía mais com os amigos...era mulherengo, mas agora sou mais responsável, tenho que dar exemplos na loja...dai não farreio mais. Bebo minhas geladas para me acalmar.(lider 1)

Não bebo, não fumo, gosto de jogar videogame. (lider 3)

Aumenta a carga de trabalho quando tá estressado, vou lá e faço as atividades. Escuto muita musica, boto meu fone de ouvido, e faço de conta que não tenho problemas; às vezes nem ligo para o que me falam, vou lá e faço meu serviço.(líder 4)

Prefiro deixar um pouco de lado a vida da familia e fazer com que dê certo por aqui; dai às vezes abro e fecho loja. Gosto de uma cervejinha, ajuda a relaxar e brinco com meus filhos, quando dá. Conversar com as pessoas me ajuda a encontrar uma resposta para as dificuldades; às vezes surgem boas ideias. (lider 5)

Dejours (2007) aponta que somos envolvidos pelo trabalho, bem além do tempo de trabalho. Temos insônia, aborrecimentos com cônjuge e filhos, sonhamos com o trabalho e toda a subjetividade é arrebatada nesse movimento, até o mais íntimo do ser. Essa busca por adaptação entra em confronto com as crescentes mudanças e cobranças do contexto de trabalho, criando o que costuma ser denominado "intersubjetividade particular" (MENDES, 2007). No entanto, o que deve ser salientado aqui é o fato de que essas estratégias não modificam a realidade, mas ajudam a manter os trabalhadores ativos, adaptando-se a pressões que lhes sejam impostas.

Sou quieto, não reclamo, não falto...tá tudo bem do jeito que ta. Sou calmo, gosto daqui. Me ajuda ficar quieto, encontro a solução, vou lá e resolvo. Para que brigar né... por isso fico na minha, a solução chega.(líder 2)

Condições de saúde no trabalho, como aponta Mendes (2007), são vivências de prazer, e para que elas aconteçam utiliza-se mecanismos capazes de satisfação e adaptação. Diante do coletado nas entrevistas, os trabalhadores não se mostram passivos frente às exigências e pressões da organização, criando estratégias para evitar condições que levem ao sofrimento. Segundo Dejours (2007), mostrar fraquezas pode implicar demissão; por conseguinte, se observa também o policiamento para a não demonstração de fraquezas, angústias ou ansiedade, para não ser substituído em função desses atributos "negativos". No entanto, esse enfrentamento para evitar sofrimento pode tornar o trabalhador insensível aos elementos ocasionadores do seu sofrimento, 
aceitando-os como um fato consumado, ou algo natural que não deve ser evitado ou combatido.

Não brigo mais com as pessoas, vou lá e faço.(lider 1)

O prazer é vivenciado quando o trabalho favorece a valorização e o reconhecimento pela realização de uma tarefa significativa e importante para a organização. Na maioria dos casos, o que é confirmado na atual pesquisa, a organização não disponibiliza as possibilidades de uma situação de envolvimento e conhecimento, por parte do líder, de todos os processos de trabalho que lhes correspondem, ou da dimensão e importância de sua produção e ação, o que se torna fator desencadeante de sofrimento:

Não vejo valorização, reconhecimento, isso deixa a gente chateado. (lider 2)

Percebe-se, aqui também, a influência de um contexto organizacional familiar onde as relações emocionais, contatos pessoais e rigidez nas cobranças interferem no processo de adaptação às atividades exigidas. A forma particular exigida pelo líder fundador, com autoritarismo e paternalismo, influencia todo o processo organizacional, inserindo instabilidade nas relações, desencadeando medo e insegurança.

Dejours (1997) afirma que executar uma tarefa sem envolvimento afetivo exige esforço e vontade, o que é suportado pelo jogo da motivação e do desejo. Assim, sua subjetividade é manipulada e seduzida, para continuação do jogo, onde o discurso manifesto é de que o trabalhador tem a perspectiva de ter seus desejos atendidos e seus sonhos transformados em realidade e, caso esse imaginário não se concretize, a responsabilidade não é da organização, mas do próprio trabalhador que não se esforçou suficientemente. Mas a constatação é de que a vivência de trabalho e realidade dos profissionais entrevistados, em relação ao trabalho e a si mesmos, alimenta-se da sensação de adormecimento intelectual, de paralisia da fantasia e da imaginação, marcando, de alguma forma, o triunfo do condicionamento em relação ao comportamento produtivo e criativo.

A gente aprende fazendo... é legal, mas as vezes faz errado... aí já viu. (líder 2)

Empurrado literalmente, hoje tá diferente, tem umas seleção aí, mas antes... era empurrado. (lider 3)

Acho que é assim mesmo, se aprende fazendo...ou vocêfaz ou tá fora, então vamos fazer (líder 4) 
O encarregado precisa conhecer bem sua função, lidar bem com sua equipe, saber o aspecto técnico para poder ensinar e ajudar. A gente aprende fazendo sabe, acho que ser líder é o dia a dia, lidar com sua equipe, dividir com eles as metas e quando a gente chega lá. (líder 5)

O líder quer se relacionar, geralmente, com o conteúdo significativo que coloca no trabalho. Quando o progresso e o avanço dessa relação são bloqueados por algum motivo ou circunstância, observa-se a incidência do sofrimento. Assim, os encarregados buscam uma possível normalidade como conquista mediante uma luta entre as exigências do trabalho e a ameaça de desestabilização psíquica e somática.

Percebe-se que existe relação entre as vivências de prazer e sofrimento no contexto de trabalho dos encarregados de empresa familiar. Os fatores que influenciam diretamente no sofrimento, detectado na fala dos líderes, são relacionados ao contexto da organização, à pressão, à dificuldade em sua formação e qualificação de suas funções e às responsabilidades inerentes à sua realidade profissional. As estratégias de defesa utilizadas são as mais variadas possíveis como, por exemplo, a busca de adaptação à realidade vivenciada. Ademais, percebe-se em seus relatos a relação do sofrimento com algumas questões inerentes à sua inserção na organização familiar e de varejo em questão.

O bem-estar psíquico no trabalho advém de uma liberdade de pensamento e ação, articulados dialeticamente como conteúdo da tarefa. Em termos de economia psíquica, o prazer no trabalho resulta da descarga de energia psíquica que a tarefa autoriza, o que corresponde a uma diminuição da carga psíquica do trabalho. Para Dejours (1997), as vivências de prazer no trabalho emergem quando as exigências intelectuais, motoras ou psicossensoriais da tarefa, relacionamento entre os pares, coesão e integração da equipe, convergem para satisfação das necessidades do trabalhador, de tal modo que a simples execução da atividade proporcione prazer:

Mal vejo minha família, chego em casa o menino tá dormindo, saio ele tá dormindo. Todo dia é bem corrido, mas é assim mesmo, eu gosto do que eu faço ser lider das pessoas é bom, responsabilidade. (lider 4)

Tem horas que a gente consegue fazer da forma que acha que é melhor, o gerente deixa, afinal de contas a gente conhece o que faz né, tem mais de quinze anos que eu faço isso, conheço um pouquinho né (risos). Não consigo fazer muitas mudanças, mas $o$ "pouquim que consigo e vejo um bom resultado fico morto de feliz, e quando vejo minha equipe bem com o que fiz, fico bem também. (líder 4) 
Para Ferreira e Mendes (2013), o prazer resulta do sentir-se útil, produtivo e aparece inseparável dos sentimentos de valorização e reconhecimento. O prazer no trabalho é vivenciado pelo sujeito quando este percebe que o que realiza é significativo e importante para a empresa e à sociedade. Ocorre quando se favorece a valorização e reconhecimento, especialmente, pela realização de uma tarefa "significativa e importante para a organização e a sociedade".

\begin{abstract}
É importante ver a satisfação dos funcionários que trabalham contigo, né? Sentir que muitas vezes você consegue ter bons resultados, ser amigos das pessoas, uma conversa que teve com aquela pessoa e ela melhora, trabalhar melhor, cresce, é promovido. (líder 4)
\end{abstract}

Eu tenho certeza que eu faço parte da empresa. A empresa tem uma participação minha pra estar onde está. E aí não tem como não se orgulhar, eu fiz aquilo lá, eu construí, eu ajudei, também faço parte dessa história. Me dediquei muito nesse setor, muita gente passou por mim e já recebi muito elogio pelo que faço.(lider 4)

Diante da análise realizada, identificam-se situações de sofrimento, mas também de prazer, na organização familiar, levando-se em consideração a realidade da gestão e características próprias apontadas nas categorias levantadas nas entrevistas com os líderes.

\title{
Considerações finais
}

A pesquisa corrobora os estudos sobre saúde mental e trabalho considerados, confirmando que existe uma relação entre organização do trabalho e sofrimento psíquico, ou seja, existe um processo gerador de sofrimento concernente a essa organização.

Como objetivo principal, investigou-se a existência e relação entre as vivências de prazer e sofrimento no contexto de trabalho dos líderes de uma organização familiar. Constata-se que existem situações desencadeadoras de sofrimento na organização familiar considerada. Por meio dos relatos desses sujeitos, identificaram-se determinadas estratégias por eles utilizadas nas situações de sofrimento.

Diante do universo organizacional familiar, com todo o seu conjunto de características e peculiaridades, percebe-se que os discursos apresentados nas entrevistas confirmam o sofrimento dos líderes diante da realidade vivenciada e que, para suportar esse sofrimento, encontram alternativas e estratégias de defesa para conseguir suportar tais condições e trabalhar com sua equipe e 
com a diretoria, realizando atividades de líderes e também de liderados. Existe a confirmação de que o trabalho perpassa e ultrapassa o contexto individual e particular da vida desses trabalhadores, interferindo nos seus momentos de lazer e de descanso.

Observou-se, neste estudo, a dimensão social da questão, na medida em que corrobora implicações que o modelo de trabalho por produção - a partir de uma estrutura familiar, que não inclui prioritariamente critérios de competência - pode causar à saúde do trabalhador. Constata-se que, para os sujeitos do caso abordado, predominam vivências de sofrimento em detrimento da auto-realização por meio do trabalho desempenhado. O predomínio da vivência de sofrimento na realidade de trabalho dos líderes tem um efeito negativo na eficácia da sua liderança, bem como em sua capacidade produtiva como um todo.

Jornadas de trabalho longas, com poucas pausas destinadas ao descanso, e/ou refeições de curta duração, em lugares desconfortáveis; turnos de trabalho noturno, turnos alternados ou turnos iniciados muito cedo pela manhã; ritmos intensos, submissão do trabalhador ao ritmo imposto pela organizaçãom sobre as quais não têm controle; pressão de chefias identificadas e modeladas por um modelo familiar de organização por mais velocidade e produtividade, todos esses fatores causam quadros de ansiedade, fadiga e distúrbios do sono, além de outras somatizações. Os níveis de atenção e concentração exigidos para a realização das tarefas, combinados com o nível de pressão exercido pela organização do trabalho desses encarregados, que se encontram entre líderes naturais familiares e líderes intermediários, podem gerar tensão, fadiga e esgotamento profissional.

Constatou-se também que existe relação entre prazer, sofrimento e organização do trabalho na organização familiar pesquisada, evidenciando-se determinadas situações que significavam, para os líderes pesquisados, momentos de prazer no seu cotidiano de trabalho.

A pesquisa não pretendeu apontar o trabalho como um agente patológico. O trabalho também pode ser visto como vitalizador da saúde humana em suas múltiplas dimensões. Contudo, isso nem sempre pareceu possível, pois, como foi apontado anteriormente, e a exemplo do que se tem na teoria sobre o tema, pareceram cada vez mais raras as situações de trabalho que favorecem a saúde mental, segundo os relatos colhidos. Assim, pode-se ratificar que o trabalho, conforme a situação, tanto fortalece a saúde mental quanto leva a distúrbios que se expressarão em termos psicossociais e/ou individuais.

Os líderes entrevistados têm consciência de que as exigências, o ritmo e toda a estrutura à qual estão submetidos podem lhes causar vários danos 
à saúde, fato explícito nos diversos relatos apontados, nos quais citam que tiveram inúmeros sintomas que podem ser caracterizados como oriundos de problemas de saúde física e mental. São flagrantes, ainda ,as alusões de temor ao desemprego e à forma como o "estar empregado seja melhor", ainda que em uma função que exija esforços sobre-humanos.

Os limites entre tempo de trabalho e tempo livre foram rompidos: fins de semana, feriados e férias são apenas motivos para pôr em dia o trabalho que está atrasado. O serviço continua de modo ininterrupto, já que as metas são, na maioria das vezes, inalcançáveis. O trabalhador não é dono de seu tempo, nem de sua vontade. Ele tem que executar funções que dependem cada vez mais da sua disponibilidade de tempo. Para isso, dispõe apenas de uma flexibilidade que, na maioria das vezes, resume-se ao discurso do empregador, sendo, na prática, o mesmo trabalho duro e adoecedor que se organizou e se organiza a partir de um sistema que privilegia poucos: os membros do círculo familiar que dominam a organização, sua burocracia e sua gestão.

Deve-se atentar para a realidade de que pessoas adoecem por causa de seus empregos; seja o trabalho a causa necessária para o adoecimento; ou, seja ele um fator contributivo e até mesmo um fator provocador (desencadeante). A exemplo do que se observou na organização familiar pesquisada, a relação trabalho e sofrimento/adoecimento é um fenômeno do qual não se pode desviar atenção, olhares e ações. Se o homem passa a maior parte de seu tempo trabalhando, suas relações pessoais fora de casa deveriam ter um valor afetivo de extrema importância, mas o contexto de cobrança vivenciado no trabalho interfere diretamente na família e momentos extratrabalho, o que pareceu uma queixa que pode se associar a determinado mal-estar do trabalho em si.

Não se pretendeu esgotar a reflexão da temática, nem generalizar para o todo das organizações e trabalhadores, mas destacar a experiência de trabalho dos líderes que vivenciam atividades estratégicas dentro de uma organização familiar específica. Sugerem-se estudos que considerem dimensões mais representativas, e que unam metodologias qualitativa e quantitativa para tratamento da temática, o que certamente contribuirá para a ampliação e aprofundamento das questões ora consideradas.

\section{Referências}

ANTUNES, Ricardo. Adeus ao Trabalho? Ensaios sobre as Metamorfoses e a Centralidade do Mundo do Trabalho. 15 Ed. São Paulo: Cortez. 2013. 216 p.

O caracol e sua concha: ensaios sobre a nova morfologia do trabalho. São Paulo. Boi-

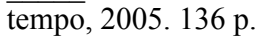

BARDIN, Laurence. Análise de Conteúdo. Lisboa, Portugal: Edições 70, 2009. 288 p. 
BARKER, C., PISTRANG, N., ELLIOT, R. Research methods in clinical and counselling psychology. Chichester, England: Wiley, 2002. 220p.

BERGAMINI, Cecília W. Psicologia aplicada à administração de empresas: psicologia do comportamento organizacional. São Paulo, Atlas, 2006. 208 p.

BOWDITCH, James. Elementos de comportamento organizacional. $3^{\text {a }}$ ed. São Paulo. Pioneira, 2011. $306 \mathrm{p}$.

CASTRO, Tthiele. Costa. Miller.; MERLO, A. R. C. Reconhecimento e saúde mental na atividade de segurança pública. Psico, Porto Alegre, PUCRS, v.42, n.4, p.474-480, out/dez. 2011.

CODO, Wanderley ; JACKSON, J. Indivíduo, trabalho e sofrimento: uma abordagem interdisciplinar. Petrópolis, RJ. Vozes, 1994. 184P.

DEJOURS, Christophe; ABDOUCHELI, E.; JAYET, C. Psicodinâmica do Trabalho: Contribuições da Escola Dejouriana à Análise da Relação Prazer, Sofrimento e Trabalho. São Paulo: Atlas. 1997. 152 p.

DEJOURS, Christophe . A Loucura do Trabalho. São Paulo: Cortez. 2003. 168 p. dez.2004.

Trabalho, subjetividade e ação. Revista Produção, [S.1.], v. 14, n. 3, p. 27-34 . set/

A banalização da Injustiça Social. Rio de Janeiro: Ed. FGV, 2007. 160 p.

EL-BATAWI, M. A. Problemas de salud psicosociales de los trabajadores en los países en desarrollo. In: Kalimo, R.; EL-BATAWI, M. A.; COOPER, Cary L. Los factores psicosociales en el trabajo y su relación con la salud. Genebra: OMS, 1988. p. 15-20.

FERREIRA, J. B.; MENDES, A.M. Entre a mobilização subjetiva e a subtração do desejo: estudos com base na psicodinâmica do trabalho. In: MERLO, ALVARO, Roberto; MENDES, Ana Magnólia. O sujeito no trabalho: entre a saúde e a patologia. Curitiba: Juruá, 2013. 292 p.

GIL, Antônio Carlos. Métodos e técnicas de pesquisa social. São Paulo, Atlas, 2009. 216 p.

GORZ, Andre. Reclaiming Work. USA: JOHN WILEY PROFESSIO, 2000. 192 p.

GRISCI, Carmem Lígia Lochins. Trabalho, tempo e subjetividade: impactos da reestruturação produtiva e o papel da Psicologia nas organizações. Psicol. cienc. prof., Brasília, v. 19, n. 1, p. 2-13, 1999.

JACQUES, Maria da Graça. O nexo causal em saúde/doença mental no trabalho: uma demanda para a psicologia. Psicol. Soc., Porto Alegre, v. 19, n. spe, 2007.

JACQUES,Maria das Graça; CODO, Wanderley (Orgs.). Saúde mental e trabalho: leituras. Petrópolis, RJ; Vozes, 2002. 142 p.

KETS DE VRIES, Manfred F. R.; CARLOSCK, Randel S.; FLOREANT-TREACY, Elizabeth. Empresa familiar no divã: uma perspectiva psicológica. Porto Alegre: Bookman, 2009. 294p.

KWASNICKA, Eunice Lacava. Introdução à administração. 6. ed. São Paulo: Atlas, 2004. $62 \mathrm{p}$. 
LACOMBE, Francisco. Recursos humanos: princípios e tendências. São Paulo: Saraiva, 2005. 515 p.

LANZANA, Antonio., CONSTANZI, Rogério. As empresas familiares brasileiras diante do atual panorama econômico mundial. In: MARTINS, J. (Coord.). Empresas familiares brasileiras: perfil e perspectivas. São Paulo: Negócio Editora, 1999. p 31-50.

LODI, João Bosco. O fortalecimento da empresa familiar. São Paulo: Pioneira,1989. 139p. . A empresa familiar. São Paulo: Pioneira, 1998. 171p.

MACEDO, Katia Barbosa. Empresa familiar brasileira: poder, cultura e decisão. Goiânia. Ed. Terra, 2000. 120p.

MENDES, René (Org.). Patologia do trabalho. Rio de Janeiro: Atheneu, 2007. 643p.

ROBBINS, Stephen Paul. Administração, mudanças e perspectivas. São Paulo: Saraiva, 2000. $368 \mathrm{p}$.

SCHEIN, Edgar H. Cultura organizacional e Liderança. São Paulo: Atlas, 2009. 414 p.

SELIGMAN-SILVA, E. Desgaste mental no trabalho dominado. Rio de Janeiro. Ed. UFRJ. Cortez,1994. 624 p.

TUPINAMBA, Antonio Caubi Ribeiro. Empreendedorismo e liderança: perspectivas e desafios atuais. Rev. Psicol., Organ. Trab., Florianópolis, v. 12, n. 1, p. 73-83, abr. 2012 .

TURATO, E. R. Tratado de metodologia da pesquisa clínico-qualitativa: construção teórico -epistemológica, discussão comparada e aplicação nas áreas da saúde e humanas. Petrópolis, RJ: Vozes, 2003. 688 p.

VERGARA, Sylvia C. Métodos de pesquisa em administração. São Paulo. Atlas, 2005. 288 p.

Submissão em: 31/0/2014

Revisão em: 18/10/2014

Aceite em: 29/11/2014

Elaine Marinho Bastos é Mestre em Administração, Psicóloga. Universidade Federal do Ceará UFC. Endereço para correspondência: Rua José Meneleu, 657 - Maraponga, Fortaleza/CE, Brasil. CEP 60714-040 E-mail: psicologia elaine@hotmail.com

Antonio Caubi Ribeiro Tupinambá é Professor associado. Doutor em Psicologia do Trabalho. Universidade Federal do Ceará UFC. E-mail: tupinamb@ufc.br

Suzete Suzana Pitombeira é Doutora em Educação. Professor adjunto. Universidade Federal do Ceará UFC. E-mail: suzetepitombeira@globo.com 